\title{
A LOOK AT THE ERRONEOUS RESTORATION OF THE HISTORICAL KASBAH OF AGADIR, MOROCCO
}

\author{
M. Nassir ${ }^{1, *}$ \\ ${ }^{1}$ Faculty of Letters and Humanities, Ibn Zohr University, Agadir, Morocco - mustaphanassir1981@gmail.com
}

Commission II - WG II/8

KEY WORDS: Diagnosis, Evaluation, Erroneous Restoration, Degradation of architectural features, Preservation, Earthen Building

\begin{abstract}
:
Architecture represents the cultural and intellectual identity of peoples. It is an authentic wealth of civilization that embodies the creative and aesthetic level that man has reached in various successive eras and historical periods (Al-Zahrani, 2012). It is a heritage that cannot be estimated and a living memory that reflects the extent of harmony between climate and the natural components of the environment on the one hand and, on the other, the economic and social systems on which man depends. Architectural heritage has received substantial attention from various entities, as it is an important historical and national project that contributes to the development of contemporary and future social structure and establishes a cultural policy building responsible community awareness. This so important considering that cultural heritage faces threats mainly related to its deterioration because of failing its preservation or undertaking inappropriate restoration work, as we illustrate by the case of the Kasbah of Agadir. The restorers with insufficient experience committed serious architectural failures in the Kasbah. It is difficult now to restore the state of the building before the restoration. They used materials that had a negative and distorting impact. As a result, these mistakes led to the destruction of the Kasbah's architectural features.
\end{abstract}

\section{INTRODUCTION}

Among the dangers that historical and archaeological sites face are those that inexperienced, unskilled or incompetent restorers cause during the process of restoration. Insufficiently studied restorations either hide some of the building's features or distort its style and distinctive architectural features. The Kasbah of Agadir has not been spared much of the erroneous restoration that occasioned damage and degradation of monuments and historic buildings. The Kasbah underwent several interventions, namely the restoration in 2002. The Italian professor of traditional industry and decoration Coco Polizzi assisted by Moroccan engineers and in cooperation with the city council of Agadir restored the walls (rampart) of the old crumbled Kasbah. Unfortunately, the restoration intervention was not satisfactory as it made adverse mistakes that affected the architectural elements of the site. This article sheds light on these mistakes and shows how they led to the destruction of the Kasbah's architectural features, A Field research was carried out with a team of Italian engineers to find out the engineering mistakes that were made in the restoration, analyze dirt and compare between the original building materials of the Kasbah and those who have been used in the restoration process.

\section{GEOGRAPHICAL DATA OF THE KASBAH}

The city of Agadir is located in Central Morocco, specifically south-west of the High Atlas mountain chain, between the longitude of nine degrees and thirty-seven minutes, nine degrees and thirty-eight minutes west of Greenwich, and between the latitudes of thirty degrees and twenty-six minutes, thirty-seven and twenty minutes north of the equator. The region is located on a slope-limited water course that extends to the estuary of Souss dry river (Al-Awaina, 1990). As for the kasbah (meaning the fort), it is located on a hilltop about 220 meters above sea level overlooking the Atlantic Ocean (Al-Awaina, 1990). This location is strategic because it meets the primary purpose for which it was built, to protect the areas surrounding the kasbah (Tazi, 1990).

\section{A BRIEF HISTORY OF THE SITE}

In the sixteenth century, the trade conflict between Spain and Portugal intensified over gaining more colonies, especially after the discovery of the sea road to India, considered a strategic way for new trade. In this context, the Portuguese managed to control the region, and in the second half of the year 1505, they built a strong fort in the Gulf of Agadir called Santa Cruz De Cabo De Gue, meaning the Holy Cross (Karim, 2006). The local population suffered from aggressions of the Portuguese occupation, a situation that the early leaders of the Saadian Dynasty exploited as the basis for their political project that led them to take control of Morocco and establish their state.

In this context, on 26 September 1540, the sultan of the Saadian state Muhammad Al-Sheikh Al-Saadi built the Kasbah of Agadir Oufella ${ }^{1}$ of mud (Astitou, 2017). The tabiah (formwork) was used in building the strong walls and towers of the Kasbah, which were equipped with cannons that severely damaged the Portuguese fort located below the Kasbah. On 12 March 1541, the Saadians led by Moman bin Yahya al-Alaj, and under the direct supervision of Muhammad al-Sheikh al-Saadi, defeated the Portuguese forces which suffered heavy losses, resulting in the surrender of their leader with a large number of soldiers (Azaykou, 1990). The victory of the Saadians was the turning point in the struggle between the two military powers, which led the Portuguese army to leave the Moroccan coasts.

* Corresponding author

1 Agadir, is an Amazigh (Berber) term that means 'collective granaries.' The site is also called "Agadir Ighir", an Amazigh term meaning 'the mountain inside the sea'. The Portuguese called it "El pico". Oufella, is an Amazigh term that means 'The high' (For more see Saber, 1990). 
After this victory, the Kasbah was a witness to several events, the most prominent of which was the earthquake that struck the city in 1960 and wiped off the architectural features of the Kasbah (Risaafi et al., 2010).

The architectural elements of the Agadir Kasbah were distinguished by aesthetic and artistic values, which testified to the skill and creativity of the Moroccan craftsmen in the field of earthen construction. The Kasbah contained impenetrable walls decorated with pyramid-shaped Crenels with a defensive role, protecting the soldiers from sniping. These walls were surrounded by rectangular towers. Between the exterior wall and the interior wall, there is a solid road that facilitates the movement of soldiers and military equipment throughout the Kasbah. The road crushed with earth. Above it is a coating that prevents seepage of water. These corridors were surrounded by several guns, including six heavy guns called "MIMOUNA".

The Kasbah had residential houses and a neighborhood for the Jews, who lived in peace with the Muslims. There was a minimarket, a dispensary, a postal center, a cafe, a mosque and marabouts.

The Agadir Ouffela Kasbah is among the historical sites and buildings censused nationwide according to the law. Dahir of March 23, 1944 (Inventory No. 1644 on April 28, 1944) classified the Kasbah walls as a national tangible heritage and considered the area around the Kasbah that extends down the hill to the road above the old sea port as a buffer zone (Law et al., 1912).

\section{ERRONEOUS RESTORATION OF THE KASBAH}

The restoration of monuments and historical buildings is intricate. It requires a high-level of technical and scientific expertise, enormous experience and long practice on the field, deep knowledge of the historical reality, architectural specificity, aesthetic and artistic values of archaeological buildings (Al-Banna et al., 2013). The causes of the degradation of monuments vary depending on the conditions that exist and their influence (Shaheen, 1993).

Random restorations which were not the subject of an in-depth consideration had the effect of blurring the architectural identity and the artistic value of the Kasbah of Agadir Ouffela. The restorers with insufficient experience committed serious architectural failures. It is difficult now to restore the state of the building before the restoration. They used materials that had a negative and distorting impact, leading a significant deterioration of the kasbah walls.

Before we enumerate these errors, we remark that this diagnosis includes just the south and east sides of the walls of the kasbah as the north and west sides were completely destroyed.

\subsection{Errors in preparing of building materials}

After a careful and in-depth look at the architectural structures of the kasbah, it becomes clear that materials with destructive effect were used in the restoration. We mention, for example:
4.1.1 Gypsum powder: High humidity dissolves a portion of gypsum, leaks it to different parts of the building, and crystallizes it when it dries up (Ibid). Laboratory analyses conducted on the materials used in the restoration of the kasbah showed a large percentage of gypsum, which occasioned cracks on its walls as a result of the local pressures that accompany the crystal growth.

4.1.2 Cement: Portland cement was used in the restoration of the kasbah of Agadir Ouffela. Therefore, dangerous cracks appeared, causing the deterioration of the historical walls and the deformation of their urban landscape. (Nassir et al., 2017) The use of cement makes the salts that it contains leak out on the surface of the walls then crystallizes them in different spots, which, added to the local pressures cause the fragmentation of surfaces and the loss of inscriptions, writings and decorations in the kasbah (Shaheen, 1993).

4.1.3 Steel: Adding steel in reinforced concrete leads to the collapse of the building constructed with soil. In case of a natural hazard, in particular an earthquake, steel generates a variable reaction and is sensitive to bending, pouring and refraction movements. It contributes to the quick collapse of the earthen building, (Boussalh et al., 2005) and the weak seismic tremors which hit the city led to cracks in the walls on the south and east sides of the kasbah.

4.1.4 Different building materials: The laboratory analysis showed a mismatch between the original building materials used to build the kasbah walls and the materials used for the restoration. The latter includes fragile materials due to the presence of low levels of lime, which is a mixture that contributes to the consistency and stiffness of the walls.

We conclude that the restorer used materials that have detrimental and destructive effects on the kasbah, a parting from mismatching the original materials used. The outcome is the disintegration of much of its original architectural components.

\subsection{At the level of engineering mistakes}

Damaging engineering mistakes made in the restoration of the kasbah resulted in the distortion and destruction of the following architectural elements:

4.2.1 The outer wall: The outer wall is about one thousand thirty meters long and six to seven meters high. Parts of it in the north and west sides were destroyed. There is a big variation in its height, which decreases the aesthetic and artistic value of the site.

4.2.2 Crenels: Crenels topped the outer wall of the kasbah and have a pyramidal shape. There are about three hundred and thirty-five crenels. Their number varies following the sections and towers. They are sixty-five to seventy centimeters high and forty-seven to fifty-three centimeters wide while the interval between them is approximately fifty-four centimeters. We note a large variation in the height and width of the crenels, which distorts the view of the kasbah. 


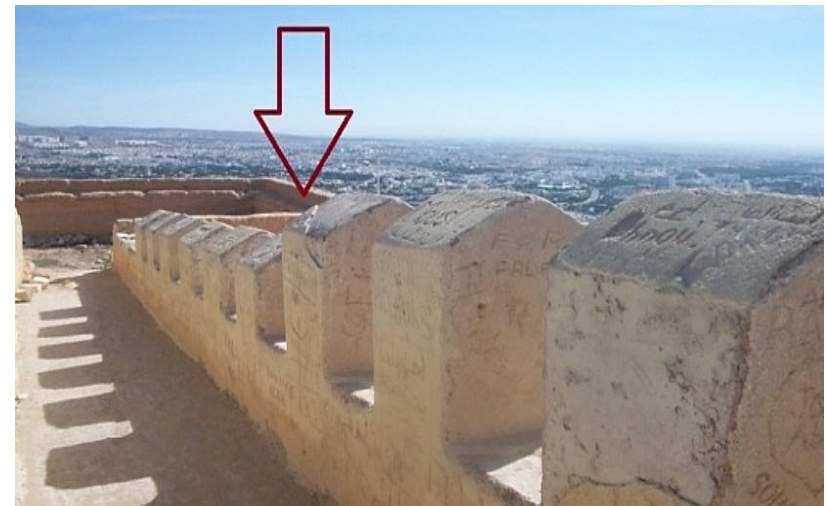

Figure 1. Difference between the height of the crenels of the Kasbah wall.

4.2.3 The inner wall: It is about one thousand and thirty meters long, fifty to sixty-five centimeters wide and one to five meters high. One of the serious mistakes made here, we find that the height of inner wall exceeds the crenels of the outer wall of the kasbah in some parts while in others the inner wall is equal to the walkway of soldiers, which results in the deterioration of the inner wall because of footsteps.

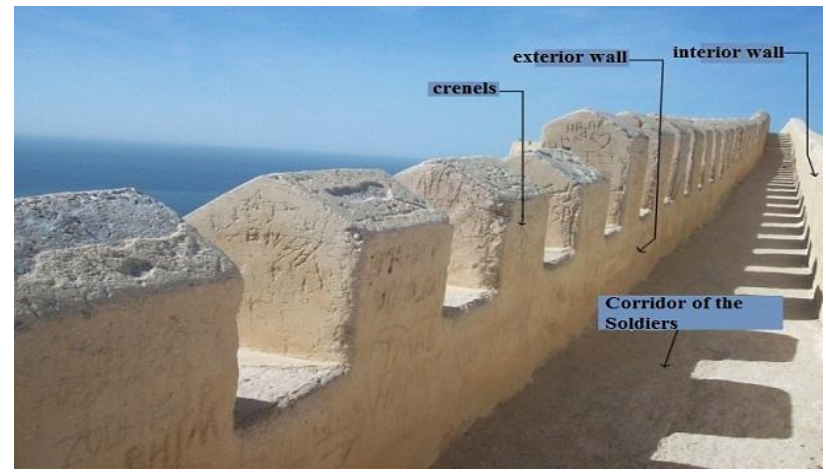

Figure 2. The inner wall above the crenels.

4.2.4 The walkway: It is between the inner and the outer walls. It is about three hundred and forty-four meters long and fifty to ninety centimeters wide. The path was built by compacting soil so that resists the movement of soldiers between different parts of the kasbah. The restorers made several mistakes when restoring the walkway. For example, they did not pave the alleys with flat stones or tiles. Therefore, water infiltrated into the foundation and walls, in addition to the narrow walkway, which threatens the safety of the site visitors.

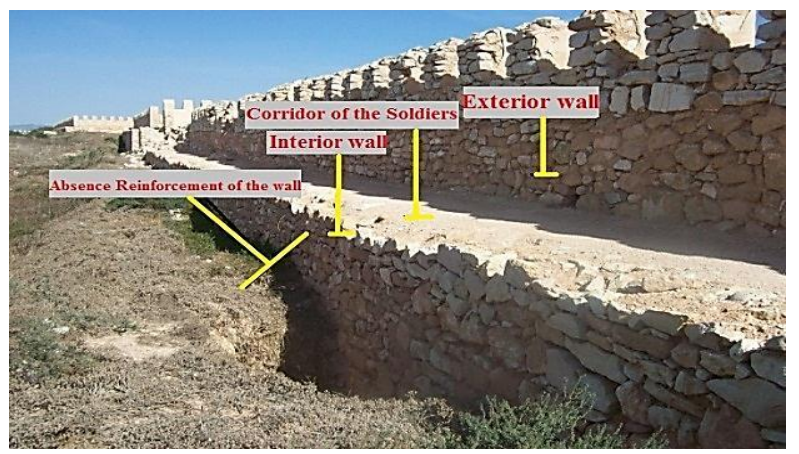

Figure 3. Degradation of the architectural elements of the kasbah due to the mismatch between building materials.
4.2.5 Towers: The Kasbah of Agadir Ouffela has three towers whose height ranges from seven to ten meters. They are decorated with crenels that vary in number from tower to tower. The first tower has four crenels and the others crumbled. The second tower has nineteen crenels two of which are crumbling and a third was completely destroyed. The third tower has nineteen crenels, including two in a deteriorating condition. The three towers are on the eastern side of the kasbah and, with field observation, it is apparent that they vary in height, between seven and nine meters. Some of them are equal to the ramparts of the kasbah to the point that it is difficult to distinguish between the tower and the kasbah wall. This is the most serious mistakes made in the restoration. In the $\mathrm{ABC}$ of military architecture, we know that towers rise above the walls to facilitate observation.

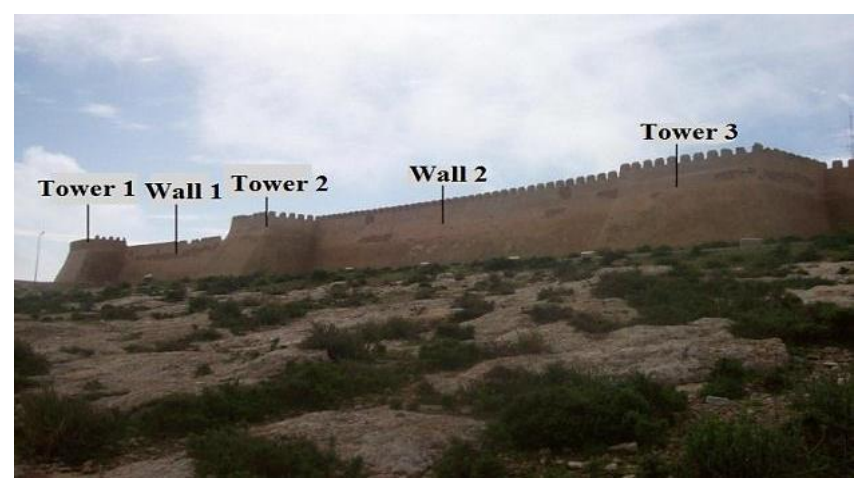

Figure 4 . The height of the wall equal to the kasbahtowers.

4.2.6 Coating: The use of materials with a destructive effect and the presence of thick layers of coating and their inconsistency led to the partial fall of the kasbah's coating (Nassir et al., 2017). The coating consists of the following materials: one hundred and sixty liters of volcanic material called "Tufs", twenty liters of lime, thirty liters of cement "CPJ 30", sixty liters of crushed sand and natural coating (Zniber et al., 2002) Furthermore, modern surface protections that are too visible nowadays, such as sandcement, glue or resin, proved to provide only a temporary protection for the earthen structures while potentially causing great damage and high expenses in the long run. Their physical and chemical properties prevent them from properly and durably adhering to raw earthen surfaces. Moreover, their use worsens the pathologies linked to moisture for lack of porosity. Their use should have been avoided whether in coating vertical or horizontal surfaces. (Boussalh et al., 2005) Laboratory analyses showed that mortar used to paint the original façade contains $62 \%$ of lime. This type of mortar is known or excellent resistance to erosion (Nassir, Ouamou, 2010).

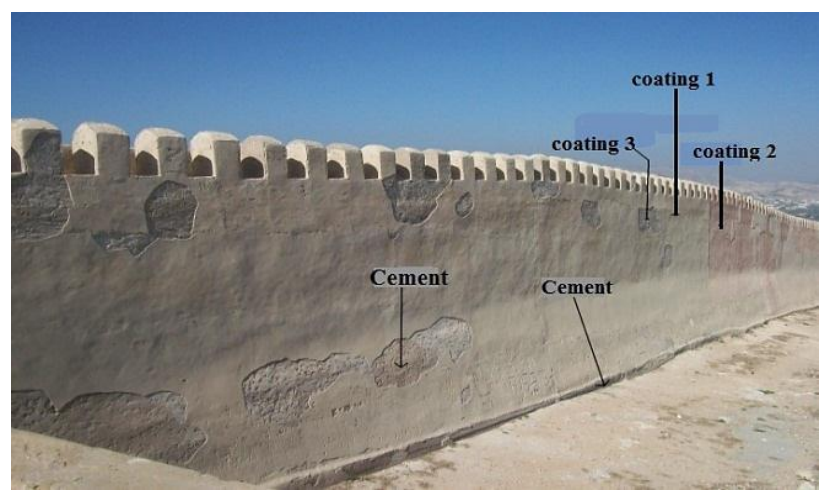

Figure 5. The wall coating damaged due to the mismatch of the components of the layers. 


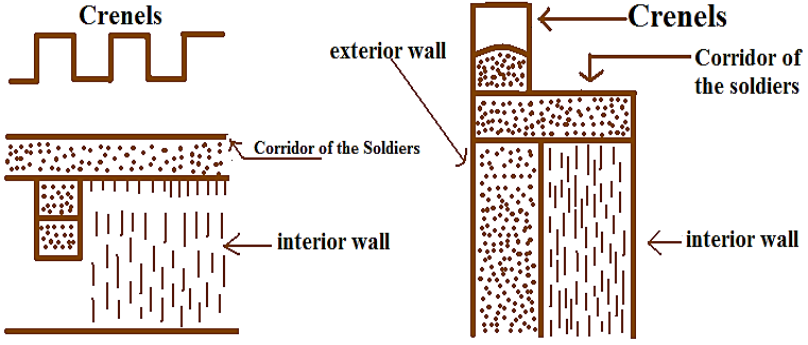

The internal and external structure of the wall

Figure 6. Longitudinal and cross-sectional design of the inner and outer structures of the kasbah walls.

4.2.7 Water drainage: The absence of a water drainage system has worsened the state of the kasbah walls, causing more and more cracks that ultimately led to the collapse of parts of the ramparts. It is taken for granted that drainpipes help protecting buildings by preventing the accumulation of stagnant water (Nassir et al., 2009).
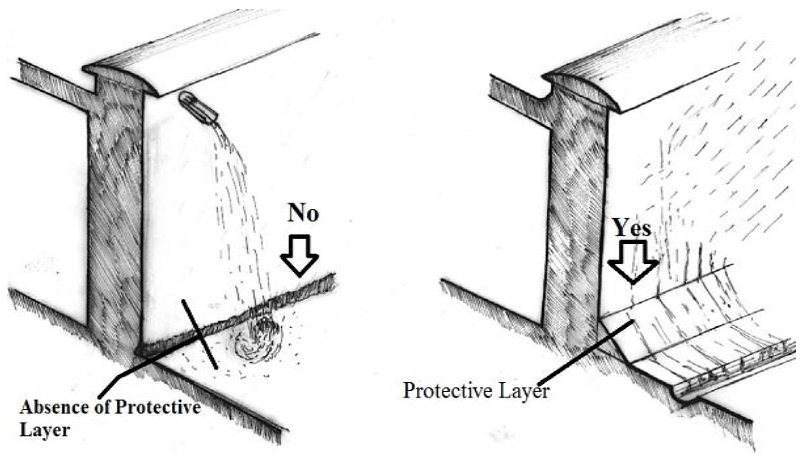

Figure 7. Protective layer.

4.2.8 Reinforcement of the wall foundations: It is noticeable that the protective layer is absent in the wall foundations. Coping is a covering of stone or terracotta or any appropriate material on the exposed top of a wall to prevent seepage of water. It plays an important role in protecting walls and foundations from erosion due to water pouring from roof scuppers and water streaming along the walls (Boussalh et al., 2005). Indeed, the absence drainpipes damaged the lower part of the walls of the kasbah.

The use of inappropriate, even damaging, materials for the restoration of the kasbah, engineering flaws and neglect of maintenance work have damaged large sections of the architectural elements of the site. Future restoration work will be a hard complicated task, especially when removing fragile chunks.

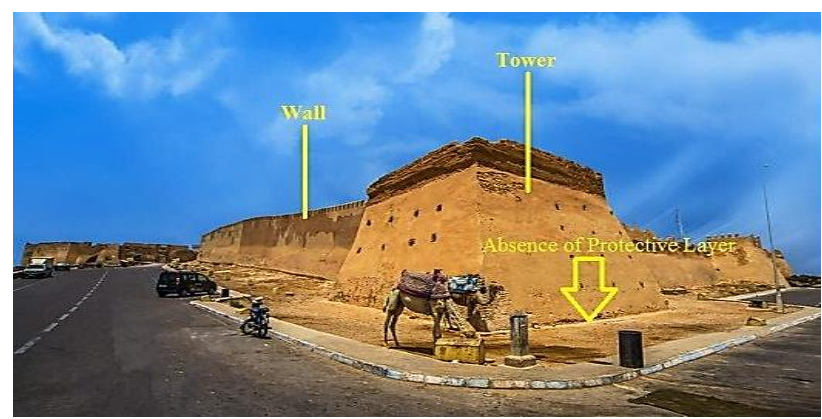

Figure 8. Absence of the Protective layer in the kasbah walls and towers.

\section{CONCLUSION}

Wrong restoration caused the destruction of the architectural components and the artistic and aesthetic values of the kasbah of Agadir. Lack of expertise and inexperience of those in charge with the preservation and maintenance has led to decisions and actions (engineering mistakes and inappropriate materials) that distorted the urban view of the kasbah. The restoration of historical sites is demanding and requires scientific expertise, aesthetic flavor and field experience and collaborative consultation among different discipline experts. Therefore, past interventions on the kasbah of Agadir should be assessed more deeply than done here to have a full grasp of future restoration work.

Finally, I would suggest a model adopted in the restoration of Ait Ben Haddou kasbah near Ouarzazate, Eastern Morocco, a tangible world cultural heritage site. A review of how the restoration of the site relied on local building techniques compatible with the local environment and in respect of national and international standards in the preservation and rehabilitation of archaeological sites is an interesting topic for future research.

\section{ACKNOWLEDGEMENT}

Many thanks to Dr. Ahmed CHAIB for supervising the $\mathrm{PhD}$ Dr. Abdelkader HERMAS for correcting and proof-reading the article. Dr. Abelouahed OUMLIL for the orientations and the observations. Dr. abderrahman OUAMOU for supervision of the work related to laboratory analysis.

\section{REFERENCES}

Al-Awaina, A., 1990. The Natural Environment of the Souss Region, Great Agadir Symposium, Printing House Najah El Jadida, Casablanca, p.25.

Al-Banna, W., Muqbel, A., Al-Iryani, S., Muhamed, A., 2013. Conservation and Restoration Of Architectural Heritage, Methods and Techniques of Restoration and Preservation of Architectural heritage, Department of Architectural Preservation of heritage environments Sanaa, p. 35.

Astitou, A., 2017. The Saadian State Aspects of Modern Moroccan History, Printing House BJ Brunt, Agadir, pp.85. 149.

Al-Zahrani, A., Nasser, A. 2012. Management of Architectural Heritage, Archaeological Studies, Series 7, King Saoud University, Faculty of Archeology and Tourism, Department of Archeology, Riyadh, p. 12.

Azaykou, A., 1990. Notes on the Construction and Call of the Portuguese Fortress (Santa-Cruz) in Agadir-N-Ighir, Great Agadir Symposium, Printing House Najah El Jadida, Casablanca, pp. 118-119.

Boussalh, M., Jalok, M., Guillaud, H., Moriset, S., 2005. Conservation manual for Earth Architectural Heritage in The Pre-Saharan Valleys of Morocco, CERKAS, UNESCO World Heritage Center, Craterre, EAG, Ouarzazate, pp.30- 38- 44.

Cerkas Center, 2005. Longitudinal and cross-sectional design of the inner and outer Structures of the Kasbah walls [Engineering drawing]. Conservation Manual for Earth Architectural Heritage in The Pre-Saharan Valleys of Morocco. 
Cerkas Center, 2005. Protective layer [Engineering drawing]. Conservation Manual for Earth Architectural Heritage in The Pre-Saharan Valleys of Morocco.

Karim, A., 2006. Morocco at the Time of the State of the Saadians, Printing House Najah El Jadida, Casablanca, p.11.

Law, 1912. The Official Journal No. 5 of November 29, 1912 and Further Modifications, 1980, (Law 22-80).

Moroccan Media Site. 2020. Absence of the Protective layer the Kasbah Walls and Towers [Image]. https:// ar. le360 .ma/ culture/164967

Nassir, M., 2017. Degradation of the Architectural Elements of the Kasbah due to the Mismatch Between Building Materials [Photograph ]. Personal Photo for Research.

Nassir, M., 2017. Difference Between the Height of the Crenels of the Kasbah wall [Photograph ]. Personal Photo for Research.

Nassir, M., 2017. The Height of the Wall equal to the Kasbah Towers [Photograph]. Personal Photo for Research.

Nassir, M., 2017. The inner wall Above the Crenels [Photograph]. Personal Photo for Research

Nassir, M., 2017. The wall Coating Damaged due to the Mismatch of the Components of the Layers [Photograph]. Personal Photo for Research.

Nassir, M. et al., 2009. Diagnosis Erroneous Restoration of the Kasbah.

Nassir, M., Ouamou, A, 2010. Personal works of Research, Earthen Sampling Analysis, Laboratory, Faculty of Letters and Humanities, Ibn Zohr University, Agadir, Morocco.

Nassir, M. et al., 2017. Diagnosis Erroneous Restoration of the Kasbah.

Risaafi, H., Jafer, I., Kicker, A.,. Memory of Agadir in the Twentieth Century, Part 3, The 1960 Earthquake, Printing House Official, Agadir, p. 11.

Saad, Z., Coco, P., Tarik, A., Alireza, A., 1998. Restoration of Agadir Ouffella, Book of Special Prescriptions, Descriptive, Estimated, Project Owner, Municipality of Agadir, Prefecture of Agadir, p.10-11.

Saber, A., 1990. The Names Given to Agadir (Between 1480 1986). Great Agadir Symposium, Printing House Najah El Jadida, Casablanca, pp. 182-185.

Shaheen, A. 1994. Restoration and Conservation of Monumental and Historic Buildings, Ministry of Culture, Egyptian Supreme Council of Antiquities, Cairo, pp. 167-172.

Tazi, A. 1990. Agadir Igher Through the Diplomatic History of Morocco, Great Agadir Symposium, printing house Najah El Jadida, Casablanca, p. 30. 